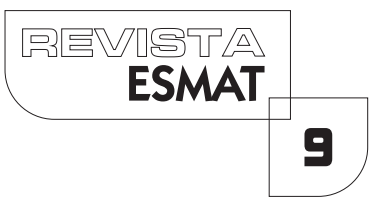

\title{
TRABALHO ESCRAVO CONTEMPORÂNEO: A DIVERGÊNCIA CONCEITUAL ENTRE A LIBERDADE DE IR E VIR E A DIGNIDADE DE VIVER
}

Shirley Silveira Andrade

Professora do curso de Direito da Universidade Federal do Tocantins, doutora pela Universidade de Brasília cujo objeto é a formação da consciência do trabalhador rural escravizado.direitoshumanospe@yahoo.com.br

\section{RESUMO}

Este trabalho tem como foco refletir a divergência conceitual entre o Grupo Especial de Fiscalização Móvel (GEFM) do Ministério do Trabalho e Emprego (MTE), no Tocantins, a respeito do delito previsto no artigo I 49 do Código Penal Brasileiro e a Justiça Federal do mesmo estado. Grande parte dos magistrados defende que essa indignidade se limita a relações de trabalho onde há perda de locomoção; os auditores fiscais, onde a dignidade do ser humano é violada. A importância desse debate está nas consequências em que essa divergência traz ao combate desse delito. A metodologia utilizada foi uma pesquisa documental realizada no MTE do Tocantins, com a análise de 23 relatórios de fiscalização dos auditores fiscais, e pesquisa em 55 processos criminais na Justiça Federal do Tocantins. Além de uma entrevista com magistrado deste estado. Concluímos que há muitas divergências entre as duas instituições que prejudicam o combate ao Trabalho Escravo.

PALAVRAS-CHAVE:Trabalho Escravo Contemporâneo. Grupo Especial de Fiscalização Móvel. Justiça Federal.

\section{ABSTRACT}

This work focuses reflect concept divergence beteween Special Mobile Inspection Group of the Ministry of Labor and Employment (MLE), in Tocantins, Brazil, about the offense referred to in Article 149 of the Brazilian Penal Code, and Justice Federal. Much of the judges of the Federal Court advocates that this indignity limited to labor relations where there is loss of movement, labors inspects when human dignity is violated. The importance of this debate is the consequences that this divergence brings to combat this crime. The methodology used is a documentary survey on MLE Tocantins, with the 
analysis of 23 inspection reports of the inspectors and research in criminal 55 cases in the Federal Court of Tocantins. In addition to the interview of a magistrate. We conclude that there are many differences between the two institutions that hinder the fight against slave labor.

KEYWORDS: Slave Labor Contemporany. Special Mobile Inspection Group. Federal Justice.

\section{INTRODUÇÃO}

Um dos pontos intrigantes sobre Trabalho Escravo Contemporâneo (TEC) é o seu conceito legal. Há estudiosos que focam o debate no limite da liberdade de locomoção, outros no desrespeito à dignidade. Pela nova redação do Código Penal a partir de 2003, o crime de reduzir alguém à condição análoga à de escravo ocorre quando, numa relação de trabalho, há escravidão por dívidas, trabalho forçado, jornada exaustiva ou trabalho degradante, condições subumanas. Um dos objetivos deste artigo é esse alcance conceitual.

A fiscalização, realizada pelo Ministério do Trabalho e Emprego (MTE) nas fazendas tocantinenses, ocorre tanto por equipes formadas em Brasília, como pelas equipes locais. Elas são responsáveis em observar se fazendas já autuadas cumprem os termos de ajuste de conduta, como averiguar se há trabalho escravo. Depois enviam seus relatórios para a Justiça Federal para que seja analisada a possibilidade da presença de crime nessas situações. Mas qual conceito de TEC é defendido pelos auditores fiscais? O que pensa o grupo que se relaciona diretamente com os trabalhadores escravizados? Divergem dos magistrados ou há pontos em comum? Em busca dessas respostas, realizou-se a pesquisa. A comparação entre esses entendimentos auxilia a refletir sobre a definição de TEC e a importância da relação entre as instituições para o combate.

A metodologia utilizada é resultado de pesquisa realizada no Ministério do Trabalho e Emprego na unidade de Palmas-TO, onde ficam armazenados os relatórios de fiscalização. Receberam bem os pesquisadores e lhes permitiram total acesso aos documentos. Foram selecionados somente os relatórios em que se caracterizou TEC. No total, foram I 5 relatórios, em 20।2; e 8, em $201 \mathrm{l}$, portanto, pesquisados 23 relatórios. Em todos eles se concluiu pela presença de TEC nas fazendas. 
Dados do Poder Judiciário Federal do Tocantins foram utilizados, bem como realizada pesquisa documental, entre 2009 e $201 \mathrm{I}$, em processos criminais finalizados que discutiam o artigo I 49 do CPB no Estado, de 1995 até 201 I . Foram 55 processos com sentenças, sem nenhuma condenação. Em 20।2, houve as duas primeiras condenações que estão em grau de recurso. Em 20 I4, mais uma, bem marcante, pois simboliza uma pequena mudança de entendimento. Importante ressaltar que todos os documentos apresentados neste artigo foram analisados a partir de formulários padronizados.

Percebeu-se grande diferença no entendimento dos auditores fiscais e o dos magistrados. Enquanto os fiscais do trabalho reafirmam a ideia de que condições subumanas de trabalho se caracterizam como trabalho escravo, grande parte dos magistrados veem essa indignidade como questão cultural e se limitam a analisar se na relação de trabalho houve limitação da liberdade de locomoção. Este artigo, num primeiro momento faz esclarecimentos quanto à terminologia Trabalho Escravo Contemporâneo, depois realiza reflexões sobre o debate legal para, afinal, analisar os dados colhidos na pesquisa.

\section{TRABALHO ESCRAVO CONTEMPORÂNEO: UMA TERMINOLOGIA CONTROVERSA}

A categoria Trabalho Escravo Contemporâneo (TEC) é fundamental para o desenvolvimento desta pesquisa. Mas antes de debater sobre sua definição, é preciso fazer alguns esclarecimentos a respeito do termo, até porque no artigo 149 do Código Penal Brasileiro (CPB) encontra-se a expressão "redução à condição análoga à de escravo".

Quadro I. Terminologia da Legislação de TEC

\begin{tabular}{|l|l|l|l|}
\hline \multicolumn{1}{|c|}{ Entidade } & Denominação & \multicolumn{1}{|c|}{ Norma } & \multicolumn{1}{c|}{ Conceito } \\
\hline $\begin{array}{l}\text { Liga das Nações } \\
/ 1926\end{array}$ & Escravidão & $\begin{array}{l}\text { Convenção } \\
\text { de } 1926\end{array}$ & $\begin{array}{l}\text { É o estado ou condição de um } \\
\text { indivíduo sobre o qual exercem, } \\
\text { total ou parcialmente, os atributos } \\
\text { do direito de propriedade. }\end{array}$ \\
\hline $\begin{array}{l}\text { OIT/ 1926 } \\
\text { e 1957 }\end{array}$ & $\begin{array}{l}\text { Trabalho forçado } \\
\text { ou obrigatório }\end{array}$ & Convenção 29 & $\begin{array}{l}\text { Todo o trabalho exigido a uma una 105 } \\
\text { pessoa mediante uma ameaça de } \\
\text { sanção ou que não se apresentou } \\
\text { espontaneamente. }\end{array}$ \\
\hline
\end{tabular}




\begin{tabular}{|c|c|c|c|}
\hline ONU/1948 & $\begin{array}{l}\text { Escravidão e } \\
\text { Servidão }\end{array}$ & $\begin{array}{l}\text { Declaração } \\
\text { Universal } \\
\text { dos Direitos } \\
\text { do Homem }\end{array}$ & $\begin{array}{l}\text { Não se refere a conceitos, apenas } \\
\text { prevê que ninguém será submetido } \\
\text { à escravidão ou servidão }\end{array}$ \\
\hline $\begin{array}{l}\text { Brasil - } 1940 \\
\text { e } 2003\end{array}$ & $\begin{array}{l}\text { Condição análoga } \\
\text { à de escravo }\end{array}$ & Código Penal & $\begin{array}{l}\text { Em 2003, prevê várias situações: } \\
\text { trabalho degradante, por dívidas, } \\
\text { forçados, com jornada exaustiva }\end{array}$ \\
\hline ONU/1966 & $\begin{array}{l}\text { Escravidão e } \\
\text { Servidão }\end{array}$ & $\begin{array}{l}\text { Pacto } \\
\text { Internacional } \\
\text { dos Direitos Civis } \\
\text { e Políticos }\end{array}$ & $\begin{array}{l}\text { Apenas prevê que ninguém será } \\
\text { submetido a tratamento } \\
\text { degradante, nem à escravidão, } \\
\text { nem à servidão nem a trabalhos } \\
\text { forçados ou obrigatórios, mas } \\
\text { ainda, como na Convenção 29, } \\
\text { permite estes trabalhos em } \\
\text { algumas situações. }\end{array}$ \\
\hline OEA/ 1969 & $\begin{array}{l}\text { Escravidão, } \\
\text { servidão, trabalho } \\
\text { forçado ou } \\
\text { obrigatório. }\end{array}$ & \begin{tabular}{|l|} 
Convenção \\
Americana de \\
Direitos Humanos \\
(Pacto São Jose \\
da Costa Rica)
\end{tabular} & $\begin{array}{l}\text { Apenas se refere que ninguém será } \\
\text { submetido a tratamento } \\
\text { degradante, nem a escravidão, } \\
\text { nem à servidão nem a trabalhos } \\
\text { forçados ou obrigatórios, mas } \\
\text { ainda como na convenção } 29, \\
\text { permite esses trabalhos em } \\
\text { algumas situações }\end{array}$ \\
\hline $\begin{array}{l}\text { Tribunal Penal } \\
\text { Inter./ } 2002\end{array}$ & Escravidão & $\begin{array}{l}\text { Estatuto de } \\
\text { Roma }\end{array}$ & $\begin{array}{l}\text { É o exercício de um poder ou de } \\
\text { um conjunto de poderes que } \\
\text { traduzam um direito de } \\
\text { propriedade sobre um ser humano, } \\
\text { incluindo o exerć́cio desse poder } \\
\text { no âmbito do tráfico de pessoas, } \\
\text { em particular mulheres e crianças }\end{array}$ \\
\hline
\end{tabular}

Fonte: Legislação Nacional e Internacional, 2012.

Organizadora: Shirley Silveira Andrade

Percebe-se, no quadro apresentado, a diversidade de termos nas legislações, mas também como a expressão Escravidão ou Trabalho Escravo é presente. Silva (20l0) faz um bom levantamento desses termos e dos seus significados: "trabalho escravo"; "trabalho em condições subumanas"; "escravidão por dívida"; "trabalho forçado"; "escravidão branca"; "escravidão contemporânea"; "redução à condição análoga à de escravo"; "super exploração do trabalho"; "formas contemporâneas de escravidão"; "nova 
TRABALHO ESCRAVO CONTEMPORÂNEO: A DIVERGÊNCIA CONCEITUAL ENTRE A LIBERDADE DE IR E VIR E A DIGNIDADE DE VIVER

escravidão"; "trabalho análogo ao de escravo"; "servidão"; "servidão por dívida"; "trabalho em condições análogas à de escravo"; "trabalho obrigatório"; "senzala amazônica", "semi-escravidão"; e "trabalho em condições análogas à escravidão”.

Ricardo Rezende (Figueira, 2004, p. 35) defende que, como a escravidão de hoje não é exatamente a modalidade da escravidão da antiguidade, ela vem acrescida de vários termos, como: semi, branca, contemporânea, por dívida ou, como prevê o Código Penal Brasileiro, condição análoga à de escravo. Ele também mostra como nas entidades governamentais os termos Escravidão e Trabalho Escravo são utilizados pelos setores do governo. Na administração de Fernando Henrique Cardoso, criou-se o Grupo Executivo de Repressão ao Trabalho Forçado (GERTRAF) para o combate ao Trabalho Escravo.

O Ministério do Trabalho e Emprego criou o Grupo Especial de Fiscalização Móvel (GEFM) de combate ao Trabalho Escravo. Em 2003, foi criado, pelo então presidente Lula, o Programa Nacional de Erradicação ao Trabalho Escravo. As Procuradorias da República e da Justiça do Trabalho se referem ao termo Escravidão ou Trabalho Escravo. Como ainda há a Comissão Nacional para Erradicação do Trabalho Escravo (CONATRAE) na Secretaria de Direitos Humanos. Como há as Comissões Estaduais denominadas de Comissão Estadual de Erradicação ao Trabalho Escravo (COETRAE). Isso demonstra que há uma construção social na utilização de Trabalho Escravo ou Escravidão.

Esses termos, na opinião da autora desta pesquisa, tornam o significado da problemática mais visível. Eles tornam as relações de poder e exploração mais claras e deixam mais marcada a gravidade do problema. Por isso, estão sendo utilizados os termos Trabalho Escravo Contemporâneo (TEC) ou Escravidão Contemporânea (EC).

\section{TRABALHO ESCRAVO CONTEMPORÂNEO: UM DIÁLOGO A PARTIR DO CONCEITO LEGAL}

O Trabalho Escravo é um fenômeno que ocorre tradicionalmente, mas foi internacionalmente questionado, principalmente pela Inglaterra, nos séculos XVIII e XIX. Em I8I 5, na Declaração relativa à abolição universal do tráfico de escravos, ficou professada a repugnância a esta prática, fundada nos princípios de humanidade e da moral universal. Vários governos se comprometeram a aboli-lo, mas não teve um efeito real, já que muitas nações, como a brasileira, não respeitaram o tratado. Todavia, já se demonstrava preocupação nesse sentido, por motivos que não serão discutidos aqui. 
Com o surgimento da Liga das Nações, adveio uma regulamentação muito importante que tem conceito marcante sobre a Escravidão: a Convenção sobre a Escravatura, de 1926. Ela definia escravidão como o estado ou a condição do indivíduo sobre o qual se exercem, total ou parcialmente, os atributos do direito de propriedade. Ou seja, o ser humano seria tratado como coisa, propriedade de outra pessoa.

Em 1930, elaborou-se a Convenção 29, da Organização Internacional do Trabalho (OIT), que guiou, por muitas décadas, o conceito de TEC no Brasil, pois o Código Penal Brasileiro (CPB) era impreciso. O termo utilizado é trabalho forçado. Esse tipo de trabalho é proibido, mas permitido, com propósitos públicos, em países que estavam no período de transição para o trabalho livre, e em situações excepcionais. Nessa legislação, trabalho forçado é todo aquele submetido a qualquer sanção ou coação e que a pessoa não tenha se oferecido espontaneamente. Aqui já aparece, de forma mais clara, o debate sobre a liberdade de locomoção e o da necessidade de não haver consentimento da vítima para a caracterização da violência. Situação que ainda influencia parte do entendimento de juízes no Brasil. Alguns consideram a presença da espontaneidade de o trabalhador ser submetido ao TEC para a decretação da pena.

O contexto da Convenção 29 tinha por objetivo, além de eliminar o tradicional Trabalho Escravo (que estamos chamando de Trabalho Escravo Moderno), reduzir as possibilidades do trabalho forçado (ou, como estamos chamando, o Trabalho Escravo Contemporâneo), daí a definição apresentada. Importante lembrar que essa legislação surgiu no período do novo colonialismo. O discurso inglês era o de que, na África, essa nova política deveria não ter a presença da Escravidão (Moderna). Segundo Holt (2005), o contrato entre a Grã-Bretanha e as colônias foi um acordo de igualdade e participação política dos habitantes das colônias.

Todavia, esse projeto político não prosseguiu. Ao invés disso, seguiu-se com trabalho forçado nas colônias. A ideia de liberação dos negros trouxe à tona uma contradição liberal. Todos os membros, nessa forma de produção, precisam participar das trocas econômicas. Os negros pobres tinham o suficiente para sobrevivência produzindo em terras, portanto, não precisavam ser trabalhadores assalariados. Daí a ideia de que negros africanos eram preguiçosos (HOLT, 2005). Diante disso, houve a necessidade do trabalho forçado para discipliná-los. Esse tipo de trabalho, no século XIX, era identificado como trabalho sob condições análogas às de escravo (COOPER, 2005), por isso, ocorreu a permissão da convenção de 1930 para trabalhos forçados ou 
TRABALHO ESCRAVO CONTEMPORÂNEO: A DIVERGÊNCIA CONCEITUAL ENTRE A LIBERDADE DE IR E VIR E A DIGNIDADE DE VIVER

análogos aos dos escravos modernos.

Muitos pesquisadores consideram o conceito da Convenção 29 como amplo, afinal englobaria não só a situação da escravidão moderna, mas também a de TEC. O problema é que essa legislação não considera vários aspectos da liberdade. $O$ debate contemporâneo do Trabalho Escravo não é somente a liberdade de locomoção, mas sim o fato de o trabalhador não ser tratado com dignidade. Portanto, mais completa é a definição da Liga das Nações, pois ela debate a liberdade de forma mais ampla, não somente a de ir e vir, mas de pensar, sentir, decidir, de ser humano. É forte na Convenção da OIT a relação entre trabalho escravo e liberdade de locomoção. O próprio nome de trabalho forçado, trabalho obrigatório, indica isso. Fato este que influencia, até hoje, parte de magistrados brasileiros. Pode-se perceber isso nos dados analisados a seguir.

\section{I Reflexões Sobre o Conceito de TEC no Código Penal Brasileiro}

A concepção contida na OIT foi muito importante para estabelecer limites à exploração humana, mas esta ideia da Convenção limita bastante as situações. Apesar de se dizer que é um conceito amplo, a definição da legislação brasileira abarca situações que não estão nessa lógica de locomoção.

Em 2003, o Código Penal Brasileiro (CPB) passou por modificações. A nova redação do artigo $149^{\text {' }}$ do CPB fechou o tipo penal e passou a exigir quatro situações principais em que se caracteriza o delito: trabalhos forçados; jornada

'Art. 149. Reduzir alguém à condição análoga à de escravo, quer submetendo-o a trabalhos forçados ou a jornada exaustiva, quer sujeitando-o a condições degradantes de trabalho, quer restringindo, por qualquer meio, sua locomoção em razão de dívida contraída com o empregador ou preposto:

Pena - reclusão, de 2 a 8 anos, e multa, além da pena correspondente à violência.

$\S 1{ }^{\circ}$ Nas mesmas penas incorre quem:

I - cerceia o uso de qualquer meio de transporte por parte do trabalhador, com o fim de retê-lo no local de trabalho;

II - mantém vigilância ostensiva no local de trabalho ou se apodera de documentos ou objetos pessoais do trabalhador, com o fim de retê-lo no local de trabalho.

§ 20 A pena é aumentada de metade, se o crime é cometido:

I - contra criança ou adolescente;

II - por motivo de preconceito de raça, cor, etnia, religião ou origem. 
exaustiva; restrição, por qualquer meio, da locomoção da vítima em razão de dívida contraída pelo empregado; e condições degradantes de trabalho. Além das formas equiparadas: retenção no local de trabalho, por cerceamento do uso de qualquer meio de transporte, e de manutenção de vigilância ostensiva ou retenção de documentos ou objetos de uso pessoal do trabalhador.

Um primeiro ponto para essa violação ser caracterizada é o de que deve haver uma relação de trabalho entre os sujeitos envolvidos, marcada pela violação grave de direitos. Pelas violações que caracterizam o delito, o objetivo dessa norma não é apenas a proteção da liberdade de locomoção, mas também o impedimento do estado de sujeição de um sujeito a outro, quando a vítima perde a possibilidade de decidir seus desígnios. É a discussão da liberdade de uma forma muito mais ampla do que a previsão da convenção 29 da OIT. Por isso, o delito tem duas principais dimensões para ser conceituado: a perda da liberdade de locomoção quando se trabalha por dívidas, ameaçado, forçado; e a perda da dignidade, no caso da jornada exaustiva e do trabalho degradante. Passemos a analisar cada uma dessas situações.

O TEC por dívidas é um clássico da realidade brasileira. Ele se caracteriza pela redução da possibilidade de decisão que um ser humano possui, submetido a uma relação de trabalho, pelo fato de estar endividado. Há vários relatos de trabalhadores(as) que ficam presos(as) às fazendas, pois se endividam para pagar seu deslocamento, e como nem sempre conseguem saldá-las, passam a trabalhar em função delas. Essa já foi a modalidade de TEC mais utilizada no norte brasileiro. Depois de tantas denúncias a respeito dessa modalidade, os fazendeiros têm-se utilizado pouco desse método para prender o trabalhador(a).

O trabalho forçado foi o guia, por muitos anos, do conceito de TEC. Viu-se como a convenção 29 da OIT limitou a discussão da escravidão a essa modalidade, levando em consideração a vontade do(a) trabalhador(a) para a caracterização do ilícito. Quando o artigo $2^{\circ}$ da Convenção estabelece como trabalho forçado todo aquele para o qual o(a) trabalhador(a) não se apresentou espontaneamente, cogita-se a análise da vontade do(a) trabalhador(a). É importante lembrar que essa convenção regulamentou as possibilidades de trabalho forçado, utilizado pelo Estado e pelas empresas privadas em 1930. No primeiro caso, poderia ser imposto a militares para a participação compulsória em obras públicas e nas prisões. Não apenas estabeleceu um conceito limitado, como ainda possibilitou a existência desse tipo de trabalho, não sendo, em todos os casos, propriamente um ilícito.

Silva (20 I 2) defende que, mesmo a convenção tendo permitido o trabalho 
TRABALHO ESCRAVO CONTEMPORÂNEO: A DIVERGÊNCIA CONCEITUAL ENTRE A LIBERDADE DE IR E VIR E A DIGNIDADE DE VIVER

forçado no período transitório, ela previa que o(a) trabalhador(a) deveria ser tratado com dignidade, mediante regras, previamente estabelecidas, de como esse trabalho poderia ser aplicado, como disciplina de salário, jornada, repouso e proibição de descontos salariais. Mas acredita-se que o fato de ainda possibilitar esse tipo de trabalho já é atentar contra a dignidade. Em 1957, a convenção 105 da OIT proibiu o trabalho forçado, mas não trouxe nova concepção desse instituto. Em seu artigo $2^{\circ}$, ela estabelece que "todo país membro da Organização Internacional do trabalho que ratificar essa convenção se compromete a abolir toda a forma de trabalho forçado ou obrigatório." A própria OIT já reconhece hoje que há formas sutis de coerção. Muitas vítimas são enganadas e aceitam o trabalho por iniciativa própria, para depois descobrirem que não são livres de abandonar o trabalho (SILVA, 20 I 2).

Defende-se que o conceito de Britto Filho (201 I, p. 245) delimita o trabalho forçado conforme a dignidade humana. Para o autor, trabalho forçado é "o trabalho que for prestado por trabalhador(a) a tomador de serviços, em caráter obrigatório, quando não decorrer da livre vontade do primeiro ou quando a obrigatoriedade for consequência, por qualquer circunstância, da anulação de sua vontade". Portanto, liga o diálogo do trabalho forçado à ideia da falta de liberdade de escolha, de agir sob coação, mas não limita o debate somente à espontaneidade do(a) trabalhador(a), discute-o a partir da anulação de consciência. Assim, se o(a) trabalhador(a) é enganado(a) ou é colocado(a) em situações que precisa aceitar essa relação de trabalho, caracteriza-se o ilícito. Hoje, nas fazendas do Brasil, essa é uma situação pouco encontrada, pois a relação de trabalho escravo é dada de forma mais sutil do que pela coação. Não há nenhum caso nos documentos pesquisados.

Outra situação em que se enquadra a relação de trabalho como escrava, é no caso da jornada exaustiva. Ela é caracterizada por Brito Filho como:

Aquela imposta a alguém por outrem em relação de trabalho, além dos limites legais extraordinários estabelecidos na legislação de regência, e/ou capaz de causar prejuízos à saúde física e mental do trabalhador, decorrente de uma situação de sujeição que se estabelece entre ambos, de maneira forçada ou por circunstâncias que anulem a vontade do primeiro. (BRITO FILHO, 2010 , p. 70)

Dessas quatro situações, aquela que mais dificuldade tem na conceituação é a do trabalho degradante, porque sua definição é menos objetiva que a das outras. Ademais, há limitação de compreensão, por parte da sociedade, da sua caracterização como trabalho escravo. Há uma visão, por um grande grupo do Poder Judiciário Brasileiro, de que no TEC não está a se discutir dignidade, mas s 
liberdade de locomoção dos sujeitos, o que simboliza uma visão do TEC a partir da convenção 29 da OIT, uma compreensão limitada dessa violência como aquela realizada sob grilhões.

O TEC é uma relação laboral que atinge a dignidade do ser humano, é o trabalho humilhante, seja por falta de pagamento, coerção, ou por um ambiente de trabalho não saudável. Ou seja, todas as situações previstas no artigo I 49 são degradantes e atingem a dignidade, mas há nelas uma especificidade que falta nessa modalidade. $O$ trabalho degradante é aquele que desrespeita, de forma grave, a dignidade da pessoa humana, porque fere direitos básicos constitucionais.

Sarlet (2012, p. 59) expõe que há duas correntes que discutem o fundamento e conceito de dignidade: a naturalista e a prestacionista. A primeira compreende a dignidade como dádiva, no sentido de que é uma qualidade ou propriedade peculiar e distintiva da pessoa humana (inata ou de origem divina). A segunda vê na dignidade o produto da subjetividade humana. Tem uma dimensão dúplice da dignidade porque é expressão da autonomia de vontade e necessidade de sua proteção por parte do Estado ou da comunidade quando fragilizada. O fato é que a dignidade implica obrigação geral de respeito pela pessoa, traduzido num feixe de direitos e deveres correlativos, de natureza não meramente instrumental.

Todavia, Sarlet (20I2, p. 7I) chama a atenção para o fato de que para se conseguir um conceito de dignidade é necessário ter como ponto de partida o fato de a pessoa concreta ter sua dignidade atingida quando reduzida a objeto, sempre que venha a ser descaracterizada e desconsiderada como sujeito de direitos. Não haverá espaço para a dignidade da pessoa humana quando faltar: respeito à vida, à integridade física e moral do ser humano; condições mínimas de existência com dignidade; limitação de poder; reconhecimento ou segurança da liberdade, da igualdade e das autonomias.

Dignidade é a qualidade intrínseca e distintiva, reconhecida em cada ser humano, que o faz merecedor de respeito e consideração por parte do Estado e da comunidade, implicando, nesse sentido, um complexo de direitos e deveres fundamentais que assegurem a pessoa tanto contra todo e qualquer ato de cunho degradante e desumano, como venha a the garantir as condições existenciais mínimas para uma vida saudável, além de propiciar e promover sua participação da vida em comunhão com os demais seres humanos (SARLET, 20।2, p. 73).

O autor defende que há indissociabilidade entre dignidade e Direitos Fundamentais, como direito à vida, à propriedade, aos direitos sociais, a uma 
jornada de trabalho razoável, ao repouso. Por isso, a discussão conceitual da modalidade de condições degradantes necessita debater a situação do ambiente de trabalho. $O$ trabalho degradante faz refletir sobre uma nova concepção de liberdade: num ambiente onde inexistem condições mínimas de trabalho, como alojamento, banheiro, alimentação, transporte, o(a) trabalhador(a) não vai efetivamente exercer sua liberdade, que não é apenas de ir e vir, mas é de pensar e de escolher.

Como ele vai poder fazer escolhas, se não tem condições mínimas de sobrevivência? De que forma vai exercer suas condições dignas de ser humano, num ambiente que o trata pior do que um animal? Por isso, há vários autores, juízes, auditores fiscais, movimentos sociais que comungam com a ideia de que trabalho degradante é aquele em que a degradação das condições sanitárias e de higiene lesiona o axioma da dignidade da pessoa humana (PRUDENTE, 2006, p. 64). Quanto às modalidades equiparadas, estas podem ser enquadradas no debate referente à limitação da liberdade de locomoção ou ao trabalho forçado. $O$ cerceio ao uso de qualquer meio de transporte, por parte do(a) trabalhador(a), com o fim de retê-lo no local de trabalho; a manutenção de vigilância ostensiva no local de trabalho; a retenção de documentos ou objetos pessoais doa) trabalhador(a), com a finalidade de prendê-lo(a) no ambiente de trabalho.

\subsection{Definição defendida pelos auditores fiscais}

Nos relatórios do TEM, percebe-se em que situações os auditores fiscais classificavam a situação como de TEC. Quanto ao sistema de Trucky Sistem (escravidão por dívidas-barracão), encontram-se alguns casos nos relatórios. Na Fazenda Imperial, em Santa Rita do Tocantins, foi registrado pelos auditores fiscais:

Sistema de armazém ou cantina - os trabalhadores foram obrigados a comprarem as botinas fornecidas pelo Sr. Tim, sendo cobrado o valor de 50,00 pelo par da botina fornecido. Também Ihes seriam cobrado o valor do gasto com a vinda dos mesmos de Minas Gerais para o Tocantins. Biscoito, desodorante, suco em pó e outras mercadorias era solicitadas ao Sr. TIM que as fornecia mediante anotação em um caderno para posterior desconto.

Nos relatórios analisados nas fiscalizações do GEFM, no Tocantins, foram encontradas situações em que os(as) trabalhadores(as) trabalhavam até 12 horas por dia. Isso porque ganham por produção. Caso não produzam, não 
recebem. Como esse trabalho é sazonal, e, por vezes, por pouco tempo, o(a) trabalhador(a) precisa trabalhar até a exaustão, com vista a levar o máximo de dinheiro para seus familiares.

Na Fazenda WR, em Cristalândia, em fiscalização realizada em 2012, os auditores fiscais relatam que o trabalho era feito até o limite das forças dos(as) empregados(as). Na fazenda Morada Verde, em Dianópolis, praticavam uma jornada diária e semanal prolongada, laborando aos finais de semana, inclusive.

Na Fazenda Gerais II, Crixás do Tocantins, em fiscalização realizada em 9 de abril de 2012, essas foram as condições de jornada encontradas: "não havia horário de almoço, a função do carvoeiro era paga por forno enchido e/ou esvaziado, não havia horário de descanso noturno, pois os trabalhadores deveriam vigiar os fornos para apagarem o fogo quando a lenha se encontrava em estado de carvão, gerando ritmo de trabalho exaustivo". A imposição de jornada não é algo tão claro. Se o(a) trabalhador(a) efetivamente ganha somente por produção, isso inviabiliza seu exercício de liberdade. de locomoção, inclusive, porque não há tempo para que descanse nem faça nada além do fato de trabalhar até o esgotamento físico.

Um dado intrigante é que, nos dados analisados, em todos os casos em que se caracterizou o trabalho escravo, nas fiscalizações do Tocantins, os(as) trabalhadores(as) estavam em condições degradantes. Isso poderia vir acompanhado de uma jornada exaustiva, de escravidão por dívidas, mas sempre o fator de um ambiente de trabalho degradante esteve presente. É como se fosse uma normalidade essas condições de trabalho na região.

Em Darcinópolis, na fazenda Buriti, em fiscalização realizada em abril de 2012 , assim que foram encontrados os(as) trabalhadores(as),

○ alojamento principal está localizado num galpão utilizado para guardar máquinas agrícolas, sementes, agrotóxicos, sal para gado e ferramentas. Feito de madeirite com várias aberturas laterais, o teto é de tela de proteção para mosquitos. O segundo alojamento está há 03 km do alojamento principal. Com cobertura de plástico e palhas de babaçu sem proteção lateral e o piso é de chão batido. Água sem tratamento, de uma cisterna no fundo do alojamento. No segundo alojamento, é usada uma água do córrego, a mesma para beber, tomar banho e lavar roupas e vasilhas.

Na fazenda Imperial, em Santa Rita do Tocantins, foram resgatados doze trabalhadores em fiscalização realizada em novembro de 2012 sob essas condições,

O alojamento é um barracão de dois cômodos, coberto por telha de amianto, proporcionado um calor intenso no seu interior. Nos quartos havia algumas 
camas e adaptações com tijolos e madeiras, onde são colocados colchões por cima... no local também são armazenados equipamentos de trabalho. Não há filtros, nem geladeira, sem mesa para alimentação, alimentação composta de arroz, feijão, macarrão, no café da manhã, apenas café preto, toma água quente direta da cisterna, frequentemente, os trabalhadores reclamavam de diarreia...

Na fazenda Vale do Canoa III, em Darcinópolis, foram encontrados oitenta e nove trabalhadores(as) espremidos(as) num alojamento em que não cabiam, com mesa de refeição para vinte pessoas, com banheiro que tinha quatro chuveiros,

com 60 empregados tinha uma área de vivência incapaz de atender todos os empregados; o local para refeição comporta no máximo 20 pessoas, obrigando vários trabalhadores comerem de pé, debaixo do sol, haja vista não há outra área coberta destinada ao descanso dos trabalhadores; banheiros que não comportavam o número de trabalhadores com apenas 04 chuveiros e vasos sanitários e um lavatório, a NR 31 exige pelo menos 07 chuveiros, 04 vasos sanitários 04 lavatórios e 07 mictórios; a fazenda canoa não tem energia elétrica nem abastecimento de água; a água do local não era potável, transportada em recipientes inadequados, próprios para combustível...

Na fazenda Santa Maria, em Marianópolis, em fiscalização realizada em setembro de 2012, quarenta e cinco trabalhadores(as) foram encontradosas) em situação de lástima. A função deles(as) era a de catar pedras numa região gigantesca onde não havia árvores. E mesmo assim, nessas condições, trabalhavam:

[..] nas frentes de trabalho não era disponibilizado aos trabalhadores área de vivência para alimentação, descanso e higiene pessoal e nem banheiros. Fazendo refeição a céu aberto, sob um sol escaldante, as fotos mostram que não haviam árvores no local,

Água advinda de uma represa, imprópria para consumo e utilizada para tudo. Alguns passando mal ao beber a água dessa represa que era muito quente dando dor de barriga, cabeça e diarreia. Água armazenada em galão de óleo lubrificante reaproveitado.

Dormiam em barracos feitos de lona preta, abertos e expostos a animais peçonhentos. Fogão de tijolos, sem local para guardar alimentos. Outra parte dos trabalhadores estava alojada em um gal pão utilizado para guardar máquinas, ferramentas, milho, sacos de sal para gado, combustível e agrotóxicos.

$\mathrm{Na}$ fazenda girassol, em Brasilândia, em fiscalização realizada em 28 de setembro de $201 \mathrm{I}$, oito trabalhadores(as) foram encontrados(as) dormindo junto com porcos, galinhas, cavalos e agrotóxicos. 
Não foram disponibilizados alojamentos adequados aos empregados. Os trabalhadores foram alojados em um curral próximo a sede da fazenda, dormindo ao lado de porcos, cavalos e galinhas. Os empregados dormiam no mesmo recinto em que os agrotóxicos eram armazenados. Não havia qualquer divisão entre estes produtos e os empregados da fazenda. Os trabalhadores tomavam banho e lavavam suas roupas em um córrego da propriedade. Não recebiam equipamentos de proteção, utilizando a própria roupa para aplicação de agrotóxico, improvisando uma camisa como máscara.

A compreensão dos auditores fiscais é a de que condições que denigrem o(a) trabalhador(a) se caracteriza como TEC, na modalidade trabalho degradante. Uma situação em que os artigos $1^{\circ}, 3^{\circ}$ e $6^{\circ}$ da Constituição Federal Brasileira estão sendo aviltamente desrespeitados. Situação em que as condições de trabalho são humilhantes.

\subsection{A Visão Conceitual de TEC na Magistratura Federal Tocantinense}

A Justiça Federal no Tocantins (JFTO) existe desde 1995, mas, apesar de este Estado estar entre os cinco primeiros, na última década, no ranking da Comissão Pastoral da Terra, como quem mais liberta pessoas, as duas primeiras condenações criminais somente ocorreram em 2012.

Foram analisados 55 processos criminais, finalizados entre 2009 e 201 I , em pesquisa realizada nesse intervalo.

Tabela I - TOCANTINS - Decisões judiciais

\begin{tabular}{|c|c|c|}
\hline DECISÃO JUDICIAL & No $^{\circ}$ & PERCENTAGEM \\
\hline $\begin{array}{c}\text { Arquivamento por } \\
\text { ausência de crime }\end{array}$ & 48 & $87,3 \%$ \\
\hline $\begin{array}{c}\text { Arquivamento por } \\
\text { falta de provas }\end{array}$ & 1 & $1,8 \%$ \\
\hline $\begin{array}{c}\text { Arquivamento } \\
\text { por morte }\end{array}$ & 1 & $1,8 \%$ \\
\hline $\begin{array}{c}\text { Arquivamento por } \\
\text { prescrição }\end{array}$ & 1 & $1,8 \%$ \\
\hline Incompetências & 3 & $5,5 \%$ \\
\hline Absolvição & 55 & $1,8 \%$ \\
\hline Total & & $100 \%$ \\
\hline
\end{tabular}

Fonte: Processos judiciais da JFTO, 2014.

Organizada por Shirley Silveira Andrade 
Esses dados demonstram que $87,3 \%$ das decisões judiciais, no período, foram para arquivar o processo, pois os magistrados não consideravam condições humilhantes como TEC. Isso corroborado pelo Ministério Público Federal, que seria o órgão responsável por realizar as acusações, mas optou por pedir os arquivamentos, com a mesma justificativa. Importante ressaltar que esta pesquisa que seguiu com as instituições, após $201 \mathrm{I}$, revela ter havido mudança de entendimento conceitual de Procuradores da República sobre TEC, a partir de $201 \mathrm{I}$, pois até então havia igualdade de compreensão entre procuradores e magistrados. Observe a opinião de procurador que pediu o arquivamento de um processo:

[...] Conquanto reconheça precariedade dos alojamentos, bem como a violação a normas trabalhistas, tenho que a dignidade dos trabalhadores não foi aviltada, sobretudo quando se tem em conta suas condições pessoais, bem como o trabalho para o qual foram contratados... Embora os trabalhadores tenham dito que na fazenda não existiam acomodações e instalações sanitárias adequadas, bem como água potável, tenho que tais irregularidades constituem apenas infrações administrativas, conforme previsto em legislação trabalhista, sobretudo, porque não há, nos autos, elementos que indiquem a existência de trabalhadores em condições degradantes, submetidos a trabalho forçado e sujeitos à violência ou coação por parte do empregador (TOCANTINS, 2008).

Esses números podem ser materializados com a decisão de um magistrado abaixo, o mesmo entrevistado. Ele defende que as condições humilhantes de trabalho são traço cultural, é um costume da região e, por isso, não deveriam se caracterizar como crime.

Lamentavelmente o quadro fático evidenciado nos autos representa a dura realidade do interior do norte do Estado do Tocantins e do sul do Pará: miséria, analfabetismo, trabalhadores rurais à margem das leis trabalhistas. Basta ver as fotografias de suas residências para se concluir que não houve redução de direitos, na verdade, nenhum sequer o Estado Ihes deu. As condições de trabalho na fazenda são só uma face do contexto de pobreza extrema em que vivem os moradores da região do Bico do Papagaio. É sem dúvida, inobservância às leis trabalhistas, mas não pode ser taxada de redução à condição análoga à de escravo, seja porque é a realidade do trabalhador rural da região, seja porque, no caso, não houve qualquer ameaça de supressão do status libertatis do trabalhador(TOCANTINS, 2007, grifo nosso).

É interessante notar que, em sua entrevista, o magistrado deixa muito clara a dificuldade de prova em relação a esses casos. E isso é um fato, pois os trabalhadores desaparecem após as fiscalizações, dificultando a ouvida dos seus 
depoimentos. Em sua entrevista, fala da dificuldade da prova para condenação. Mas, ao observar suas decisões, percebe-se que não são justificadas por falta de prova, elas são fundamentadas no fato de que as péssimas condições de trabalho não caracterizam crime. Essa postura revela a sua posição do problema.

Em entrevista realizada por esta pesquisadora, o magistrado revela que, primeiramente, devem-se resolver os conflitos em áreas de conhecimentos diferentes da criminal, esta deve ser utilizada em última instância. Justifica seu posicionamento pela falta de orientação aos proprietários, o Ministério Público do Trabalho falha nessas orientações, por isso, ocorrem tantas infrações. Chega a dizer que querem transformar um problema administrativo num problema de polícia. O magistrado segue com a ideia de que há exagero dos auditores fiscais nas fiscalizações, e prefere acreditar que sua atuação é contraditória

É importante notar que, em praticamente todos os processos criminais analisados, os trabalhadores não foram ouvidos perante o magistrado. Somente há documentação, os seus depoimentos no momento da fiscalização. Perguntado se ele já esteve presente nalguma operação do MTE, respondeu que não. Acrescentou que era importante a Justiça Federal julgar os processos criminais, pois não teria o envolvimento emocional que há na Justiça do Trabalho. Portanto, ele conhece o problema a partir dos documentos juntados peloMTE.

Hoje há entendimento divergente na própria Justiça Federal Tocantinense, mas ainda bastante tímida, como expressa em sentença condenatória proferida em 20 I 4, cujos argumentos coincidem com os dos fiscais do trabalho já aqui expostas.

\section{CONCLUSÕES}

Diante dessa discussão apresentada, percebe-se haver postura díspar entre a magistratura federal e os auditores fiscais do trabalho quanto à definição do TEC. O que é preocupante, pois o combate ao TEC somente é eficaz se feito por meio da atuação convergente entre as instituições.

O Brasil já tem políticas de combate em todas as esferas do Poder Público. No Poder Legislativo, á mudança na Constituição Federal no artigo 243, como modificações no Código Penal a respeito, até legislações estaduais que proíbem o poder público de realizar licitação com empresas já enquadradas como praticantes do trabalho escravo pelo MTE. No âmbito do Poder Judiciário, há o combate na Justiça do Trabalho com indenizações trabalhistas, ações civis públicas, ações de indenização e ações criminais na Justiça Federal. E no Poder 
Executivo, tanto a atuação do grupo móvel, como a existência do Cadastro Nacional de Empregadores, das multas, do incentivo aos bancos em não fornecer crédito para os integrantes dessa lista.

Mas o descompasso entre instituições sobre o que é trabalho escravo tem atrapalhado o combate. Se por um lado os auditores fiscais multam os fazendeiros, obrigam-nos ao pagamento dos direitos trabalhistas, resgatam os trabalhadores e fazem um grande esforço para juntada de provas para caracterizar o delito, a Justiça Federal não reconhece como crime essa violação. O que gera um ambiente favorável para o desrespeito. É necessário um processo de articulação entre as instituições para a efetividade desse combate. Se há grande divergência entre elas, a escravidão é favorecida.

\section{REFERÊNCIAS}

ATLAS Político-jurídico do Trabalho Escravo Contemporâneo. Organizado por Antonio filho, Nonato Masson, Reynaldo Costa. Açailândia: Ética, 201 I .

BARACAT, Eduardo Milléo. (coordenador). Direito Penal do Trabalho: reflexões atuais. Belo Horizonte: Fórum, 2010.

BRETON, Binka Le. Vidas roubadas: a escravidão moderna na Amazônia Brasileira. São Paulo: Edições Loyola, 2002. Tradução de Maysa Monte Assis.

BRITO FILHO, José Claudio Monteiro. Trabalho com redução à condição análoga à de escravo: análise a partir do trabalho decente e de seu fundamento, a dignidade da pessoa humana. In: VELLOSO, Gabriel, e FAVA, Marcos Neves. Trabalho escravo contemporâneo: o desafio de superar a negação. São Paulo: LTr, 2006, p. 132-133.

.Trabalho decente: Análise jurídica da exploração do trabalho-trabalho escravo e outras formas de trabalho indigno. 2. Ed. São Paulo: LTr, 20 I 0.

- Trabalho Escravo: elementos para a caracterização jurídica. In: Trabalho Escravo Contemporâneo: um debate interdisciplinar. Organizador por Adonia Antunes Prado, Ricardo Rezende Figueira e Horácio Antunes de Sant'Anna Junior. Rio de Janeiro: MauadX, 20 I I . p. 24I-250.

FIGUEIRA, Ricardo Rezende. Pisando Fora da própria Sombra: a escravidão 
por dívida no Brasil contemporâneo. Rio de Janeiro: Civilização brasileira, 2004.

PALO NETO, Vito. Conceito jurídico e combate ao trabalho escravo contemporâneo. São Paulo: Ltr., 2008.

PLASSAT, Xavier. Abolida da escravidão?: In: Trabalho escravo contemporâneo no Brasil: contribuições críticas para sua análise e denúncia. Rio de Janeiro: Editora UFRJ, 2008, p. 73-96.

PRUDENTE, Wilson. Crime de escravidão: uma análise da Emenda Constitucional 45 de 2004, no tocante às alterações da competência material da Justiça do trabalho, e do novel status constitucional dos tratados internacionais de direitos humanos. Rio de Janeiro: Lumen juris, 2006.

SAKAMOTO. Os acionistas da casa grande: a reinvenção capitalista do trabalho escravo no Brasil contemporâneo. In: Olhares Sobre a escravidão contemporânea: novas contribuições críticas. Org. por Ricardo Rezende Figueira e Adonia Antunes Prado. Cuiabá: EdUFMT, 20 I I , p 37 I -40 I .

. Os acionistas da Casa-grande: a reinvenção capitalista do trabalho escravo contemporâneo. Tese de doutorado apresentada ao programa de pósgraduação em ciência política da Universidade de São Paulo. São Paulo, 2007. Orientação do Dr. Cláudio José Torres Veiga.

SILVA, Marcelo Ribeiro. Trabalho análogo ao de escravo rural no Brasil do século XXI: novos contornos de um antigo problema. 20 I 0. Dissertação de mestrado pelo Programa de Pós-Graduação em Direito Agrário da Universidade Federal de Goiás-UFG. Orientado pela professora Doutora Silzia Alves Carvalho Pietrobom.

UBIRATTAN, Cazeta. $\bigcirc$ trabalho escravo ainda resiste. In: As possibilidades jurídicas de combate à escravidão contemporânea. Brasília: Organização internacional do trabalho, 2007.

TOCANTINS. JUSTIÇA FEDERAL. Ação penal n 2005.43.00.I350-2. Autor Ministério público Federal. Réus: Joaquim de Faria Daflon, Joaquim Faria Daflon filho, Geseimar, José Luiz Mateus dos Santos. Ia Vara Juiz - José Godinho Filho. Palmas, 30/7/2007. 
TRABALHO ESCRAVO CONTEMPORÂNEO: A DIVERGÊNCIA CONCEITUAL ENTRE A LIBERDADE DE IR E VIR E A DIGNIDADE DE VIVER

TOCANTINS. JUSTIÇA FEDERAL. Ação penal n 2008.43.00.002157-9Pedido de arquivamento. Autor Procurador Alexandre Moreira Tavares dos Santos. I ${ }^{a}$ Vara Juiz Adelmar Aires Pimenta da Silva. Palmas, 29/8/2008. 